\title{
Levels of energizing drive and learning of tasks of different difficulty levels'
}

ARJUN P. PUROHIT

QUEEN'S UNIVERSITY, KINGSTON, ONTARIO

Twenty Ss were divided into hi-SRT and lo-SRT groups on basis of their scores on the Serial Reaction-time Test (SRT). The hi-SRT group performed significantly better than the lo-SRT group in all the items of a nonsense syllable learning task irrespective of the difficulty values of the items, except in the case of extremely easy items. Implications of this finding on the relationship between energizing drive and learning of difficult tasks have been discussed.

Spence and the followers of his theory believe that high drive leads to better performance in easy but worse performance in difficult tasks (Spence, 1956). This prediction has been amply verified in verbal learning experiments (e.g., Standish \& Champion, 1960; Spence, Farber, \& McFann, 1956, etc.). Most of these experiments use Manifest Anxiety Scale (MAS) (Taylor, 1953) to discriminate drive levels since, in terms of Spence's theory, anxiety can be regarded as an index of Hullian general drive. However, recently Eysenck and his associates have reported that persons under induced drive did in fact perform better than persons without induced drive in both easy and difficult verbal learning tasks (Willet \& Eysenck, 1962; Willet, 1964).

One possible explanation of such contradiction of findings on the relationship between drive and performance on difficult tasks lies in the dual nature of drive. It has often been indicated that drive is energizing as well as disrupting in nature (e.g., Jones, 1960). However, it is also possible, as indicated by some, that there are two different kinds of drive-energizing and disrupting-and that disrupting drive is quite close to anxiety (Sarason, 1957). When Hull formulated his theory on the facilitating effect of drive, most probably he had energizing drive, and certainly not disrupting drive, in mind. The results of anxiety studies, therefore, have no serious bearing on this aspect of Hull's theory. This exploratory experiment is designed to study the relationship between individual differences in energizing drive and learning of verbal materials of different difficulty levels.

Serial Reaction-time Test (SRT) has been used in this study as measure of individual difference in energizing drive. This test discriminates very well dysthymics and hysterics, who are known to have high and low drive levels respectively (Claridge, 1961; Eysenck \& Claridge, 1962) but correlates slightly but significantly with anxiety and neuroticism scales $(-.24$ with MASand -.15 with Maudsley Personality Inventory $-\mathrm{N}$ Scale) (Purohit, 1966). Purohit (1966) also reports that SRT scores correlate positively and significantly with conditioned GSRs.
Another feature of this experiment is that various levels of difficulty of learning items were estimated on the basis of difficulty involved in learning them instead of any preconceived criteria.

Our hypothesis was a straightforward Hullian one: persons with high energizing drive will perform better than persons with low energizing drive in verbal learning at all levels of difficulty.

\section{Subjects}

Twenty male students of Introductory Psychology at Queen's University volunteered to be the Ss of this experiment. The Ss were not aware of the purpose of the experiment.

\section{Serial Reaction-Time Test (SRT)}

An SRT apparatus was built in accordance with the description given by Claridge (1961). It consisted of five lights arranged horizontally 2 in. apart on a vertically inclined wooden panel. Three in. below each light, there was a switch. During operation, if a light was on, it could be switched off by pressing the switch below it. The Ss were required to switch off the light as fast as they could. Thus the test was a self-paced one. The sequence of 50 lights was random, except that no light appeared twice in succession. Total number of correct responses for five continuous minutes was recorded for each $\mathrm{S}$ and was regarded as his SRT score.

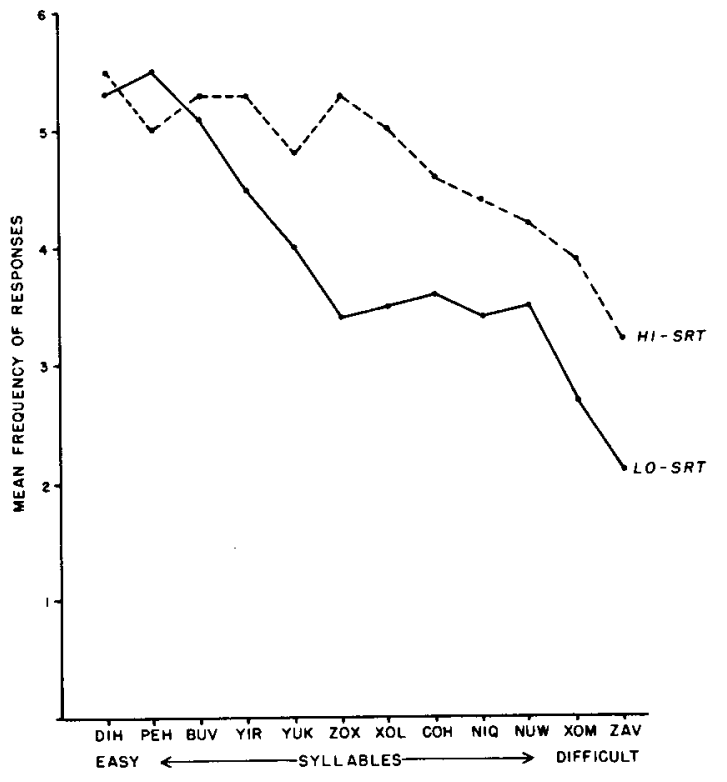

Fig. 1. Performance of hi- and lo- SRT groups on nonsense syllables of different difficulty levels. 


\section{Leaming Task}

Immediately after the SRT, the Ss learned a list of 12 nonsense syllables, which had pronounceability ratings between 4.27 and 5.91 (Underwood \& Schulz, 1960) and meaningfulness values between 27 and 40 (Glaze, 1928).

The nonsense syllables were projected on the wall about $5 \mathrm{ft}$. in front of the $\mathrm{S}$ by a Kodak Carousel-800 Projector. Each syllable was projected for 5 sec. At the end of each trial, the $S$ was asked to recall as many syllables as he could. The whole list was presented for six trials in the same order.

\section{Results}

The Ss were divided into two groups-hi-SRT and lo-SRT-on the basis of their scores on the SRT. Difficulty values of the nonsense syllables were estimated on the basis of total frequency of recall score obtained by the syllables from all Ss. Figure 1 shows the mean frequency of responses of Ss in hi- and lo-SRT groups on each syllable arranged in terms of their difficulty value. It clearly indicates that though the two groups do not differ too much on the three easy syllables, the hi-SRT group shows its unmistakable superiority over the loSRT group in the rest of the nine more difficult syllables. In the case of the first three syllables, the difference between the two groups was not noticeable probably because responses of both the groups were very near the ceiling. Analysis of variance performed on the data gives a significant $F$-ratio for difficulty values of the nonsense syllables $(F=10.31, \mathrm{df}=11, \mathrm{p}<.01)$, a significant $F$-ratio for the two groups ( $F=5.21, \mathrm{df}=1, \mathrm{p}<.05$ ) and a not-significant $F$-ratio for the interaction between groups and syllables $(\mathrm{F}=1.54, \mathrm{df}=11)$.

Since the syllables were presented in the sameorder, we had also an opportunity to examine the performance of the two groups in terms of the serial positions of the

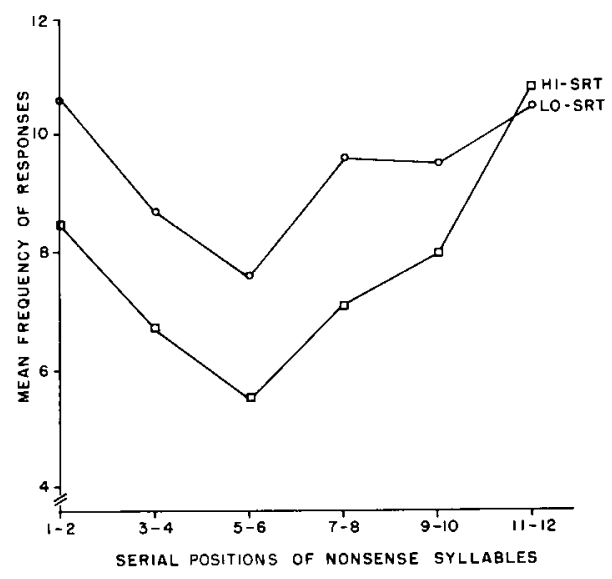

Fig. 2. Performance of hi- and lo- SRT groups on different serial positions. syllables. Figure 2 illustrates this relationship. From this figure the familiar curvilinear relationship between performance efficiency and serial position is quite clear. It also indicates that the relative superiority of the hi-SRT over the lo-SRT group remains constant in all positions except towards the end of the list.

\section{Discussion}

The implication of the results of this study is obvious: if SRT can be regarded as measure of individual difference in energizing drive, then persons with high energizing drive perform better than those with low energizing drive in verbal learning tasks regardless of difficulty level. These results are quite in harmony with those of Eysenck and Willet as well as with the predictions from Hullian theory.

We meant the study to be an exploratory one and used only 20 Ss. Therefore, replications of this study are warranted before any serious conclusions can be arrived at. Nevertheless, the clear and significant support obtained in favor of the old-fashioned Hullian hypothesis regarding facilitatory effect of drive on performance does indicate the possibility of this aspect of Hullian theory being in good shape.

\section{References}

Claridge, G. S. Arousal and inhibition as determinants of performance of neurotics. Brit. J. Psychol, 1961, 52, 53-56.

Eysenck, H. J., \& Claridge, G. S. Position of hysterics and dysthymics in a two-dimensional framework of personality description. J. abnorm. soc. Psychol., 1962, 64, 46-55.

Glaze, J. A. The association value of nonsense syllables. J. genet. Psychol., 1928, 35, 255-269.

Jones, H. G. Learning and abnormal behaviour. In H. J. Eysenck (Ed.), Handbook of abnormal psychology, New York: Basic Books, 1960.

Purohit, A. P. Personality variables, sex-difference, G.S.R. responsiveness and G.S.R. conditioning. J. exp. Res.. pers., 1966. 1, 166-173.

Sarason, I. G. Effects of anxiety and two kinds of motivating instructions on verbal learning. J. abnorm. soc. Psychol., 1957, 54, 166-1.71.

Spence, K. W. Behavior theory and Conditioning. New Haven: Yale University Press, 1956.

Spence, K. W., Farber, I. E., \& McFann, H. H. The relationship between anxiety (drive) level to performance in competitional paired-associate learning. J. exp. Psychol., 1956, 52, 296-310.

Standish, R. R., \& Champion, R. A. Task difficulty and drive in verbal learning. J. exp. Psychol., 1950, 59, 361-365.

Taylor, J. A. A personality scale of manifest anxiety. J. abnorm. soc. Psychol., 1953, 48, 285-290.

Underwood, B. J., \& Schulz, R. W. Meaningfulness and verbal learning. New.York: J. B. Lippincott Co., 1960.

Willet, R. W. Situation-induced drive and paired associate learning. In H.. J. Eysenck (Ed.), Experiments in motivation. London: Pergamon Press, 1964.

Willet, R. A., \& Eysenck, H. J. Experimentally induced drive and difficulty level in serial rote learning. Brit. J. Psychol., 1962, $53,35-29$.

Note

1. This research was supported by National Research Council of Canada. 